\title{
ORIENTAÇÕES E INSTIGAÇÕES PRESENTES NA BASE NACIONAL COMUM CURRICULAR QUANTO AO USO DE TECNOLOGIAS DIGITAIS NO ENSINO
}

\author{
ORIENTATIONS AND INSTIGATIONS PRESENT IN THE COMMON NATIONAL CURRICULAR \\ BASE REGARDING THE USE OF DIGITAL TECHNOLOGIES IN TEACHING
}

ORIENTACIONES E INSTIGACIONES PRESENTES EN LA BASE CURRICULAR NACIONAL COMÚN SOBRE EL USO DE LAS TECNOLOGÍAS DIGITALES EN LA EDUCACIÓN

\author{
João Ferreira Sobrinho \\ Junior \\ (iD) 9 \\ Mestrado em Ciência da \\ Computação (UFPE) \\ Técnico em Assuntos \\ Educacionais (UFG) \\ Discente da Pós-Graduação em \\ História (UFG) \\ joffersoju07@hotmail.com
}

\section{Cristina de Cassia Pereira Moraes \\ (iD) 9}

Doutorado em História das Ideias

(Universidade Nova de

Lisboa/Portugal)

Professora Adjunta da Faculdade de História (UFG)

Professora da Pós-Graduação em História (UFG)

cristinadecassiapereiramoraes@gm ail.com

\begin{abstract}
Resumo
O objetivo deste artigo é identificar as orientações e instigações ao uso das tecnologias digitais presentes na BNCC. Para responder a tal cenário se dispôs de pesquisa documental e bibliográfica para o levantamento, coleta e análise dos dados de forma qualitativa. Nesse sentido, primeiramente fundamentamos as discussões acerca da BNCC e das tecnologias digitais, como também, destacamos suas imbricações com o ensino. E por fim, nos perscrutamos no texto da BNCC, com fins a identificar e elencar as instigações e as referências ao uso das tecnologias digitais aos quais estão presentes nesse corpus normativo. E como resultado da pesquisa, identificamos que a BNCC orienta e instiga o uso de tecnologias digitais em toda a educação básica. Esse norteamento parte de três tópicos bases: as competências gerais; competências específicas por áreas; e, o item denominado as tecnologias digitais e a computação. Em relação ao primeiro tópico, destaca-se a competência 4 e 5 . No segundo, temos que todos os componentes curriculares possuem orientação ao uso de tecnologias digitais. E no terceiro, é destacado a importância da apropriação das tecnologias digitais pelo estudante com fins não apenas aos seus estudos escolares como também à sua vida cotidiana. Conclui-se então que a BNCC orienta e instiga os alunos e professores à apropriação e uso das tecnologias digitais tendo em vista que está presente em todos os campos da atividade humana e dessa forma a educação não pode se desatrelar a isso.

Palavras-chave: Tecnologia Digital. Ensino. Política Educacional. Base Nacional Comum Curricular. Competências.
\end{abstract}

Recebido em: 1 de julho de 2021.

Aprovado em: 28 de setembro de 2021.

Como citar esse artigo (ABNT):

SOBRINHO JUNIOR, João Ferreira; MORAES, Cristina de Cassia Pereira. Orientações e instigações presentes na base nacional comum curricular quanto ao uso de tecnologias digitais no ensino. Revista Prática Docente, v. 6, n. 3, e079, 2021. http://doi.org/10.23926/RPD.2021.v6.n3.e079.id1248 


\section{Abstract}

The objective of this article is to identify the guidelines and incentives to the use of digital technologies present in the BNCC. To respond to this scenario, a documentary and bibliographic research was used to survey, collect and analyze the data in a qualitative way. In this sense, we first grounded the discussions about the BNCC and digital technologies, and also highlighted their imbrications with teaching. And finally, we scrutinized the text of the BNCC, in order to identify and list the instigations and references to the use of digital technologies that are present in this normative corpus. As a result of the research, we identified that the BNCC guides and encourages the use of digital technologies throughout basic education. This guidance is based on three basic topics: the general competencies; specific competencies by area; and, the item called digital technologies and computing. Regarding the first topic, competencies 4 and 5 stands out. In the second, we have that all curricular components are oriented towards the use of digital technologies. And in the third, the importance of the appropriation of digital technologies by the student is highlighted, not only for his school studies but also for his daily life. We conclude that the BNCC guides and encourages students and teachers to appropriate and use digital technologies, considering that they are present in all fields of human activity, and that education cannot be detached from this.

Keywords: Digital technology. Teaching. Educational Policy. Common National Curricular Base. Competencies.

\section{Resumen}

El objetivo de este artículo es identificar las directrices e incentivos al uso de las tecnologías digitales presentes en el BNCC. Para responder a este escenario, se utilizó la investigación documental y bibliográfica para el relevamiento, la recolección y el análisis de datos en forma cualitativa. En este sentido, primero fundamentamos las discusiones sobre el BNCC y las tecnologías digitales, así como, destacamos sus imbricaciones con la enseñanza. Y por último, escudriñamos el texto del BNCC, para identificar y enumerar las instigaciones y referencias al uso de las tecnologías digitales que están presentes en este corpus normativo. Y como resultado de la investigación, identificamos que el BNCC orienta y fomenta el uso de las tecnologías digitales en toda la educación básica. Esta orientación se basa en tres temas básicos: las competencias generales; las competencias específicas por áreas; y, el punto denominado tecnologías digitales e informática. En relación con el primer tema, destacan las competencias 4 y 5 . En el segundo tenemos que todos los componentes curriculares están orientados al uso de las tecnologías digitales. Y en el tercero, destaca se la importancia de la apropiación de las tecnologías digitales por parte del alumno, no sólo para los estudios escolares sino también para su vida cotidiana. Concluimos que el BNCC orienta y estimula a los estudiantes y profesores a la apropiación y uso de las tecnologías digitales, considerando que están presentes en todos los campos de la actividad humana $\mathrm{y}$, por lo tanto, la educación no puede estar desconectada de ellas.

Palabras clave: Tecnología digital. La enseñanza. Política educativa. Base Curricular Nacional Común. Competencias. 


\section{NOTAS INTRODUTÓRIAS}

A legislação educacional é uma temática de grande relevância, pois é nela em que são dispostas as orientações advindas das relações de embates estabelecidas entre os atores do campo da educação. Nesse campo, gestores públicos e privados do âmbito educacional como também presentes na esfera executiva federal, estadual e municipal. Além de professores, alunos e a comunidade escolar, representadas pelos seus entes associativos, dentre outros atores se estabelecem em diálogos e disputas que vão e voltam, se moldam e recriam, perfazendo com que sejam necessárias orientações normativas que planificam um acordo/contrato temporário entre esses atores através da legislação educacional, ou seja, ela é um reflexo dessas lutas e embates dentro do campo educacional. Logo, a Base Nacional Comum Curricular (BNCC) está circunscrita como legislação educacional e assim, provem desse mesmo mecanismo de embate entre os atores do campo da educação.

No mundo de hoje a tecnologia digital está presente em todos os campos da atividade humana, e dessa forma a sociedade é impactada e se movimenta dia a dia a partir dos seus avanços e limitações. Desde o acordar ao dormir o indivíduo faz uso de tecnologias digitais mesmo sem se dar conta. Entre os aparatos digitais destaca-se o smartphone, o notebook e o computador de mesa, muito embora estas seriam de menor utilidade se a rede mundial de computares não existisse. Em vista a esse cenário, o campo educacional não poderia sair incólume dessa sociedade tecnológica, e por conseguinte o ensino implementado nas instituições escolares formais ou mesmo em contextos não formais foram diretamente incluídos nessa revolução tecnológica, já que a cada dia que passa torna-se cada vez mais impensável impedir ou separá-la dessa miscelânea. Pois, o que resta é entender os seus mecanismos e buscar nas boas maneiras os melhores contextos e particularidades à inserção das tecnologias digitais no ensino hodierno.

O campo educacional é permeado por agentes que movimentam sua dinâmica, e estes são estabelecidos por atores políticos, educacionais, sociais que permeia esse campo. Nem sempre os agentes podem se entrecruzar porquanto seus objetivos seres díspares, mas de outro lado podem ser aliados ou complementares para o fazer educação. Ao discorrermos sobre BNCC e as tecnologias digitais, temos dois agentes que movimentam a dinâmica da educação, não apenas nacionalmente, como no caso da BNCC, mas também no mundo inteiro como a tecnologia digital está presente. Assim, realçarmos as imbricações entre esses dois agentes é 
salutar para entender seus objetivos individuais e em conjunto de forma integrada, com fins ao ensino público de qualidade.

A metodologia desta pesquisa se baseia no viés documental e bibliográfico da pesquisa qualitativa. Essas duas tipologias de pesquisa são semelhantes, mas se diferencial a partir do olhar e sua sobre a natureza de suas fontes. Enquanto a pesquisa baseada na bibliografia se baseia nos aportes que advém de trabalhos revisados por pares, a pesquisa documental se estabelece em material que não foram analiticamente tratados (GIL, 2002).

Em relação a coleta, análise e discussão dos dados, inicialmente nos aprofundamos em identificar em separado sobre a BNCC como também às tecnologias digitais no que se refere às suas imbricações com o ensino. E por fim, elencamos as instigações e as referências ao uso das tecnologias digitais aos quais estão presentes no corpus textual da BNCC com o propósito de se alcançar o objetivo desta pesquisa.

O objetivo deste artigo é identificar as orientações e instigações ao uso das tecnologias digitais presentes na BNCC. Este trabalho tem importância, pois a tecnologia digital é uma questão fortemente presente hodiernamente, e ainda mais na faixa etária dos estudantes, e além do mais a BNCC é uma das principais referências normativas à educação no Brasil. Logo, ao debruçarmos sobre as instigações presentes na BNCC que se referenciam ao uso de tecnologia digital, torna a pesquisa sobre essa temática justificável.

\section{A BNCC E AS TECNOLOGIAS DIGITAIS: AGENTES ATIVOS NO CAMPO EDUCACIONAL}

Cada tempo histórico possui suas características particulares e que estas influenciam os vários campos de atividade humana, e nesse meandro a educação não está alheia a tais mudanças. Dessa forma, os modos de se ensinar que perpassaram os séculos anteriores não são exatamente os mesmos que temos na contemporaneidade, muito embora algumas representações podem ser assemelhadas. Em meio a tais mudanças novos desafios são postos à mesa e assim, devem ser enfrentados.

\footnotetext{
Houve um tempo em que a tarefa de educar era vista por seus protagonistas - tanto professores como alunos - como algo pleno de sentido [...]. Ainda são muitos os que acreditam que assim é e continuará sendo, ontem, hoje e sempre. Estes são aqueles que veem na educação o melhor e principal instrumento para ajudar as pessoas a se prepararem para uma vida plena, uma cidadania participativa, uma posição econômica digna e suficiente, uma convivência não conflituosa, uma apreciação adequada da cultura e das relações sociais em constante processo de mudança. Contudo, proliferam - e às vezes ruidosamente - os que asseguram que já não é mais assim. Seria incoerente educar para a convivência, a solidariedade, a paz, etc, quando em torno da escola, a sociedade se mostra individualista, competitiva ou agressiva (ENGUITA, 2004, p. 7).
} 
Dentre esses problemas, destacamos o currículo. Os currículos aplicados em décadas ou séculos, por vezes são classificados como retrógrados e ultrapassados por não trazerem de certa forma, o suprir das exigências nas quais são impostas pelas relações estabelecidas no contexto social e temporal de determinado grupo. Nesse sentido, Reis e Oliveira (2018) destacam a problemática ao qual a discussão em torno do currículo é posta nos dias de hoje no Brasil.

\begin{abstract}
A problemática curricular torna-se ainda mais complexa quando analisamos as profundas transformações que vivenciamos na sociedade contemporânea, marcada cada vez mais pelo avanço da ciência, do conhecimento, da informação e das tecnologias. É nesse contexto que buscamos refletir, neste capítulo, sobre os atuais dilemas da constituição do currículo no Brasil, considerando sua relevância no processo de construção de uma escola pública de qualidade para todos como expressão dos direitos sociais (REIS; OLIVEIRA, 2018, p. 2).
\end{abstract}

Tal problemática é trazida até mesmo à definição do próprio conceito do que é o currículo, pois nas palavras de Libâneo, Oliveira e Toschi (2003) é realçado que:

Há muitas definições de currículo: conjunto de disciplinas, resultados de aprendizagens pretendidas, experiências que devem ser proporcionadas aos estudantes, princípios orientadores da prática, seleção e organização da cultura. No geral, compreende-se currículo como um modo de seleção da cultura produzida pela sociedade para a formação dos alunos; é tudo que se espera seja aprendido e ensinado na escola (LIBÂNEO; OLIVEIRA; TOSCHI, 2003, p. 362)

Nesse sentido, nota-se a complexidade que há no diálogo acerca do currículo, muito embora podemos deduzir que muito do propósito deste é estabelecer a informação que será transmitida ao aluno. Em vista disso, o currículo é um fator primordial dentro do contexto escolar, pois é nesse onde "os aspectos pedagógicos, organizativos e políticos se expressam" (REIS; OLIVEIRA, 2018, p. 4). Além do mais, o currículo não é estabelecido por uma mão somente e sim, é através do embate que há entre os atores do contexto educacional sendo eles gestores públicos, professores, alunos, coordenadores, dentre outros.

Assim, ao debruçarmos sobre o tempo atual onde as tecnologias e o advento da internet trouxeram à nossa sociedade uma globalização síncrona e conectada em maior ou menor grau, os alunos antes passivos das informações que lhe eram transmitidas, passaram a buscar de forma mais autônoma - através das redes digitais - o conhecimento antes apenas disponível nas escolas ou nas bibliotecas, e dessa forma modificando as concepções de se ensinar e de se aprender (SILVA; SILVA, 2017).

Nesse panorama a escola não deve estar alheia à sociedade que a constitui, e com isso o ensino tende a se apropriar das mesmas ferramentas nas quais os seus participantes (alunos, professores, gestores municipais, dentre outros) também estão se apropriando em sua vida cotidiana, e nesse caso temos da tecnologia. Sendo assim, os currículos na contemporaneidade 
vão aos poucos aderindo ao ambiente tecnológico na qual estão inseridas através de suas atualizações, modificações e inovações inerentes a elas. E por conseguinte, desafios são postos à escola com fins a adequar as velhas práticas as novas práticas, a partir de ferramentas de ensino aprendizagem condizentes com a sociedade que o rodeia, e em nosso caso a sociedade da informação. É importante se destacar que ao se falar em ferramentas não se trata de desenvolvimento propriamente de algum programa ou recurso tecnológico, e sim esse termo ferramenta denota um meio, modo, jeito, forma, método, técnica, procedimento, metodologia ou mecanismo de se construir o caminho para a apropriação do conhecimento pelo aluno de forma favorável.

Após destacarmos algumas considerações sobre o currículo e questões que perpassam esse tema, passaremos a destacar mais especificamente a BNCC e as tecnologias digitais. A BNCC é um dos mais importantes norteadores da educação no Brasil. Esta foi homologada em 2017 para o ensino infantil e fundamental e em 2018 para o ensino médio, perfazendo sua abrangência por todo ensino básico em um documento único, com previsão de implementação total até 2022.

A BNCC é um documento com caráter normativo que está orientado pelos princípios éticos, políticos e estéticos à formação integral do estudante, buscando com isso uma sociedade inclusiva e democrática, tal qual é apregoado pelas Diretrizes Curriculares Nacional da Educação Básica. Os preceitos da BNCC são baseados em um conjunto progressivo de aprendizagens essenciais aos estudantes da Educação Básica, com fins que lhes sejam assegurados o direito à aprendizagem conforme preceitua o Plano Nacional de Educação - PNE, como apresenta o documento.

\begin{abstract}
A Base Nacional Comum Curricular (BNCC) é um documento de caráter normativo que define o conjunto orgânico e progressivo de aprendizagens essenciais que todos os alunos devem desenvolver ao longo das etapas e modalidades da Educação Básica, de modo a que tenham assegurados seus direitos de aprendizagem e desenvolvimento, em conformidade com o que preceitua o Plano Nacional de Educação (PNE). Este documento normativo aplica-se exclusivamente à educação escolar, tal como a define o $\S 1^{\circ}$ do Artigo $1^{\circ}$ da Lei de Diretrizes e Bases da Educação Nacional (LDB, Lei ${ }^{\circ}$ 9.394/1996), e está orientado pelos princípios éticos, políticos e estéticos que visam à formação humana integral e à construção de uma sociedade justa, democrática e inclusiva, como fundamentado nas Diretrizes Curriculares Nacionais da Educação Básica (DCN). (BRASIL, 2018, p. 7)
\end{abstract}

$\mathrm{Na}$ BNCC se apresentam as competências, habilidades e aprendizagens gerais para o ensino básico em todo o território nacional, buscando dirimir e nivelar o ensino com vistas a elevar a qualidade deste de forma uníssona. Um ponto a ser destacado é que a BNCC não é um currículo pronto para todas as unidades da federação ou municípios, mas sim um conjunto de 
diretrizes que guiarão as redes públicas federais, estaduais e municipais de ensino, como também das instituições particulares, a construírem os seus próprios currículos (BRASIL, 2018).

Historicamente temos que a BNCC é um documento que já tinha planejamento de criação desde a Constituição de 1988 (BRASIL, 1988) quando em seu artigo 210, prediz a fixação de conteúdos mínimos para o ensino fundamental, a fim de que se assegure a formação básica comum e respeito aos valores culturais e artísticos, nacionais e regionais. Após algum tempo, a Lei de Diretrizes e Bases da Educação Nacional - LDB de 1996 dá prosseguimento nesse caminho destacando em seu artigo 26, que os currículos da educação infantil, fundamental e médio devem seguir uma orientação comum, cabendo os sistemas de ensino que fazem parte desse amaranhado de redes complementarmente estabelecer uma parte diversificada a partir de questões regionais e locais da sociedade, cultura e economia do lugar.

Art. 26. Os currículos da educação infantil, do ensino fundamental e do ensino médio devem ter base nacional comum, a ser complementada, em cada sistema de ensino e em cada estabelecimento escolar, por uma parte diversificada, exigida pelas características regionais e locais da sociedade, da cultura, da economia e dos educandos. (BRASIL, 1996, p. 1)

Nos anos que se seguiram, os Parâmetros Curriculares Nacionais - PCN de 1997 e 1998 $\left(1^{\mathrm{a}}\right.$ e $2^{\mathrm{a}}$ fase do ensino fundamental) e o de 2000 para o ensino médio, reforçaram a necessidade de um amplo debate sobre a consolidação de uma base comum. A partir daí Resoluções, Portarias, Seminários, Conferências e Reuniões, consolidaram a primeira versão da BNCC, disponibilizada em 16 de setembro de 2015.

No período temporal concorrente à construção da BNCC, temos um outro agente que galgou passos largos nesse período e que passou a ser presença constante no campo da educação, apresentamos as tecnologias digitais. Elas estão presentes indiscutivelmente em nossa sociedade sendo parte das relações sociais dos jovens e ganhando cada vez mais espaço entre as demais faixas etárias, assim sendo somente com esse dado já teríamos razões suficientes para sua investigação como ferramenta mediadora no processo de aprendizagem. Assim sendo, Costa, Duqueviz e Pedroza (2015) destacam como as tecnologias digitais impactam e influenciam fortemente os sujeitos e podem contribuir consideravelmente na aprendizagem.

\footnotetext{
As novas tecnologias parecem influenciar e impactar a constituição de sujeitos dos usuários em grande potencial das tecnologias digitais, de modo que os aprenderes a conhecer e a fazer perpassam o acesso à internet, além dos aprenderes a conviver e a ser implicarem em comunicação virtual com família e amigos. (COSTA; DUQUEVIZ; PEDROZA, 2015, p. 608)
} 
Denota-se que o aprendizado com mediação de tecnologias digitais tem potencial para alcançar a todos ao ter outro aspecto de interação, fomentando com isso novos contextos para a produção do conhecimento através da informação recebida. Dessa maneira, se corrobora com a sociedade integrada e globalizada na qual vivemos onde a tecnologia é usada de forma rotineira ao ser empregada nos mais simples afazeres cotidianos. Sob esse cenário não se poderia pensar que essa tecnologia digital estaria longe do contexto escolar, pois está com os alunos no celular ou com os professores ao planejar suas aulas, ou seja, sua utilização já é presente no cotidiano escolar. Ademais, possui boas possibilidades de utilização, tanto dentro da estrutura física da escola em um ensino formal, como também em um contexto não formal de aprendizagem.

Isso posto, nota-se a urgência em um diálogo onde as formas de ensinar e as formas de comunicação entre escola-aluno devem ser repensadas, reinventadas, readaptadas, ou seja, se abrindo a novos horizontes fora da zona de conforto do ensino tradicional, predominante no Brasil. Esse diálogo deve seguir o caminho inverso de apenas seguir a reprodução conteudista, ao se inserir novos elementos com a finalidade de estimular a colaboração, a ludicidade e o protagonismo do aluno (SAVIANI, 1991).

Nesse contexto, as tecnologias digitais podem contribuir ao possibilitar a inserção de contextos de aprendizagem que incitam novas experiências ao aluno estimulando a colaboração mútua através do lúdico, e nesse espaço o professor assume seu papel de mediador da informação. No entanto, deve-se atentar para a necessidade do bom planejamento e boa relação entre os professores e os alunos, além de que o conteúdo deve ser propício e adequado o uso de tecnologias digitais, sob o risco de apenas ser uma reprodução de uma aula dita tradicional, ao invés de trazer para a cena uma vivência significativa de aprendizagem. Esse pensamento é corroborado por Parada (2011) quando discorre que aparatos digitais como o computador, jogos eletrônicos, blogs, internet são meios de comunicação mais atrativos que a exposição oral do professor, no entanto isso não pode ser o único quesito para a seleção e organização dos materiais, trazendo com assim uma valorização do objeto tecnológico com fins em si mesmo. Tal direcionamento trará consequência a meras substituições, como do livro didático pelos aparatos digitais, aula tradicional por uma aula digitais mais divertida, ou seja, dissimulando o velho no novo ao dar uma aura de encanto e magia para o uso das tecnologias digitais, mesma essa sendo apenas aparente. 
Não há dúvidas de que o computador, a internet, jogos eletrônicos, blogs etc. possam veicular informações de modo mais atraente do que a exposição oral do professor seguida de exercícios pelos alunos. Entretanto, a atratividade não pode ser tomada como critério maior para a seleção e a organização das atividades de ensino. Por mais desejável que seja, não pode ser valorizada como um fim em si mesma.

\begin{abstract}
A simples substituição de livro didático pelos aparatos tecnológicos, a mudança de um suporte para outro, pode ser uma forma de modernização conservadora, um formato novo para velhos conteúdo, uma espécie de maquiagem que até sugere diferenças sem, contudo, mudar a face do ensino. Isso significa que a "aura de magia" atribuída às TICs pode adicionar efeitos especiais, no movimento mesmo de manter o enredo anterior. (PARADA, 2011, p. 81)
\end{abstract}

Logo, para que as tecnologias digitais realizem um trabalho a contento como um instrumento mediador da aprendizagem é necessário um olhar mais apurado sobre o contexto, e a partir disso repensando a prática, o aluno poderá ter realmente novas experiências de aprendizado que o estimule em questões que se perfazem a crítica e a reflexão do conteúdo. E dessa forma, os atores do contexto da escola devem dialogar e aprender mais da relação entre essas tecnologias e o ensino nesses tempos de pandemia e de uma sociedade globalizada através da tecnologia.

\title{
3 A BNCC E AS ORIENTAÇÕES E INSTIGAÇÕES AO USO DAS TECNOLOGIAS
}

A BNCC foi construída sob o fundamento de competências. Essas competências representam a mobilização de conhecimentos, habilidades, atitudes e valores para resolver questões do cotidiano, do mundo do trabalho e para exercer a cidadania. Na BNCC as competências foram fixadas em número de dez para a educação básica, que estão vinculadas ao: Conhecimento; Pensamento científico, crítico e reflexivo; Repertório cultural; Comunicação; Cultura Digital; Trabalho e projeto de vida; Argumentação; Autoconhecimento e autocuidado; Empatia e cooperação; e, Responsabilidade e cidadania.

Essas competências gerais estão distribuídas por todo o ensino básico, e assim tem uma progressão ao passar dos anos escolares com a finalidade de se adaptar ao aluno de acordo com seu desenvolvimento.

No sentido das orientações e instigações ao uso das tecnologias digitais a BNCC define algumas aprendizagens fundamentais no âmbito pedagógico para assegurar aos estudantes o seu pleno desenvolvimento, através das dez competências gerais. Dessa forma, dentre essas dez competências gerais, temos duas que possuem relação com tecnologia digital. Esta orientação 
está vinculada na quarta e integralmente na quinta competência geral da BNCC (BRASIL, 2018) chamada de cultura digital, descrita a seguir.

- Competência 4 na qual se instiga ao uso de diferentes linguagens - verbal (oral ou visual-motora, como Libras, e escrita), corporal, visual, sonora e digital -, bem como conhecimentos das linguagens artística, matemática e científica, para se expressar e partilhar informações, experiências, ideias e sentimentos em diferentes contextos e produzir sentidos que levem ao entendimento mútuo.

- Competência 5 na qual se busca compreender, utilizar e criar tecnologias digitais de informação e comunicação de forma crítica, significativa, reflexiva e ética nas diversas práticas sociais (incluindo as escolares) para se comunicar, acessar e disseminar informações, produzir conhecimentos, resolver problemas e exercer protagonismo e autoria na vida pessoal e coletiva.

Ao se falar sobre a quarta competência se destaca o tipo de linguagem digital que deve ser instigada, ou seja o modus de uso/modus operandi que o ser conectado se conecta aos demais seres conectados. Dentro da rede mundial de computadores, várias formas de interrelações virtuais podem ser construídas, através das redes sociais, blog, wiki, plataformas, dentre outras. E dessas interrelações virtuais, se constrói a linguagem digital que de forma alguma está dissociada dos demais tipos de linguagens. Nesse cenário, o aluno deve estar integrado a linguagem digital, no entanto sem se desprender das demais, pois o homem é um ser complexo sob vários aspectos próprios, tal qual o aluno está em contato constante na sociedade presencial e virtual, e deve se apropriar das variadas linguagens advindas dos canais de comunicação existentes nos dias de hoje (MORIN, 2007).

A quinta competência é fortemente enraizada na tecnologia digital, o que nos faz perceber sua importância e a sua inevitável influência dentro de nossa sociedade atual. Essa competência traz em seu bojo indicações claras acerca do uso responsável das tecnologias digitais pelos alunos, indicando termos como: comunicação de forma crítica e reflexiva; ética no uso e no acesso; e, produzir conhecimentos, como forma de indicar a diretriz a ser seguida. Além disso, os primeiros termos trazem vocábulos interessantes como: compreender; utilizar e criar tecnologias digitais (BRASIL, 2018). Logo, a instigação ao uso de tecnologias digitais na BNCC é perceptível.

Sobre essas duas competências, nota-se que estão alinhadas com as novas formas de se receber a informação no século XXI, onde a sua velocidade e os impactos individuais e 
coletivos são absorvidos em fração de segundos, amplificando assim seus resultados dicotômicos e maniqueístas pela sociedade conectada. Esse quadro reforça a necessidade do estudante se guiar pelo senso crítico e reflexivo do pensar em si e no outro, com ou sem o uso de tecnologias digitais.

Seguindo as orientações de uso de tecnologias constantes na BNCC, percebemos que essas orientações percorrem desde a educação infantil até o ensino médio, ou seja, toda a educação básica. Assim, na educação infantil o uso tecnológico é inserido quando se trata dos Direitos de aprendizagem e desenvolvimento, ao indicar que se deve explorar movimentos, ritmos, sons, formas, texturas, cores, emoções, relacionamentos, objetos, elementos naturais "na escola e fora dela, ampliando seus saberes sobre a cultura, em suas diversas modalidades: as artes, a escrita, a ciência e a tecnologia" (BRASIL, 2018, p. 38).

Nesse âmbito é destacado as diversas modalidades de saberes culturais, ou seja, o campo onde os alunos - mesmo menores - devem conhecer, com a finalidade de se apropriar e fazer uso racional e benéficos para si e para outrem. Assim, o profissional de educação não teria mais a possibilidade de se esquivar da tecnologia, pois ela aí está como afirma Kenski (2001) quando diz explanada que independentemente de os profissionais da educação serem contrários ou não ao uso das tecnologias digitais, estes devem enfrentar os desafios que provém da inserção dessas tecnologias no ensino. No entanto, isso não é algo para ser imposto ou inserido de qualquer forma e sim, o profissional deve conhecer as tecnologias digitais a partir de suas vantagens e desvantagens e com isso, adequá-las aos momentos apropriados e contextualizados dentro de seu planejamento para então "transformá-las em ferramentas parceiras em alguns momentos e dispensá-las em outros instantes" (p. 61).

Além do que, o profissional deve estar capacitado para realizar essa relação entre o conteúdo a ser ministrado em sala de aula e a tecnologia adequada ou sua melhor forma de disposição, em um sentido que traga problematização e reflexão ao seu aluno a partir do método e técnica utilizada de forma pedagógica e simples. Esse pensamento é corroborado por Behar (2008) quando cita que o uso das tecnologias digitais deve ser pensado como um recurso pedagógico multifacetado, pois este pode ressignificar e reestruturar informações apreendidas anteriormente, produzindo com isso novos conhecimentos. Ou seja, não é apenas se utilizar das tecnologias digitais e sim, "é preciso problematizá-los e produzir novas relações numa pedagogia reflexiva" (p. 6). Sendo assim, o professor estar preparado para utilizar das 
tecnologias no ambiente educacional ao qual se encontra, com vistas a não somente aplicar a tecnologia por ela mesma, mas integrada ao seu planejamento e uso pedagógico nas aulas.

Prosseguindo então com as referências da tecnologia digital na BNCC. Assim nos deparamos com as competências específicas de área, item presente em todas as etapas da educação básica no BNCC. Para o ensino fundamental a temática das competências específicas de área é mais delimitada, enquanto no ensino médio esta se apresenta mais abrangente e é tratada no âmbito das ciências humanas e sociais. Desse modo, passaremos a tratar distintamente essas etapas, ensino fundamental e médio da educação básica no que se refere às competências específicas de área.

No ensino fundamental as competências específicas de todos os componentes curriculares possuem referências e instigações ao uso das tecnologias digitais. Vamos exemplificar pela área de história. Na história, as competências específicas estão em número de sete e uma é bem explícita ao uso das tecnologias digitais. Esta discorre que o estudante deve "Produzir, avaliar e utilizar tecnologias digitais de informação e comunicação de modo crítico, ético e responsável, compreendendo seus significados para os diferentes grupos ou estratos sociais" (BRASIL, 2018, p. 402). Nessa competência específica de área, percebemos a importância dada às tecnologias digitais no âmbito escolar como também no extramuros, ao instigar não somente o uso, mas a produção e criação de forma ética, sempre levando em conta as características comuns do lugar em que se propõe fazer-se acontecer. Isso é relevante, pois se distancia do modus operandi do uso pelo uso, e se aproxima do uso reflexivo, ético e responsável das tecnologias digitais pelos atores escolares.

Para o ensino médio, essa competência se vislumbra de forma mais geral ao estar presente no campo das ciências humanas e sociais. Nesse contexto, a competência específica relacionada a tecnologia digital é pautada na análise dos processos políticos, econômicos, sociais, ambientais e culturais em suas diversas sociedades e temporalidades, sob a égide da pluralidade epistemológica do conhecimento com fins ao estudante "compreender e posicionarse criticamente em relação a eles, considerando diferentes pontos de vista e tomando decisões baseadas em argumentos e fontes de natureza científica” (BRASIL, 2018, p. 570). Nesse sentido, o uso da tecnologia se torna mais amplo e crítico no processo epistemológico, se baseando em vários pontos e aspectos na complexidade social e científica entre o homem consigo mesmo e com a sociedade que o circunda. 
No geral percebemos que o uso da tecnologia digital é instigado progressivamente de acordo com a sequência entre os anos da educação básica. A partir de tal cenário se percebe que para a educação infantil o estímulo criativo e curioso é destacado com a finalidade do desenvolvimento motor do educando nessa faixa etária. Acerca do ensino fundamental o direcionamento partir do uso, criação, proposição de tecnologias digitais deve levar em conta aspectos morais, críticos, éticos para si e para os outros, além de indicar possibilidades para construção do entendimento de questões cotidianas em que as tecnologias digitais podem influir em seu contexto. Já para o ensino médio, se observa uma relação mais ativa entre o educando e a tecnologia digital. Nesse direcionamento o estudante é posto em posição a deixar seu papel passivo e passar a ter um papel ativo em seu aprendizado, utilizando-se também para isso, a criação, proposição e divulgação das tecnologias digitais. Assim, por ele ter maior acesso os meios digitais sua função passa a ser de proatividade, utilizando-se deles para seu desenvolvimento e apropriação das competências e habilidades propostas pela BNCC, tal qual os profissionais de educação devem utilizá-las para os fins do ensino.

Além dessas orientações gerais e específicas de competências e habilidades para o ensino fundamental e médio presentes na BNCC, ela dispõe de um tópico somente para tratar das tecnologias digitais, este denominado: As tecnologias digitais e a computação. Nesse tópico é destacado que elas estão presentes em nossa vida cotidiana, além do que a informação como fonte de conhecimento é cada vez mais armazenada digitalmente, e que isso traz a importância do conhecimento de uso e o acesso a essas informações que tendem a ser um caminho que crescerá exponencialmente. Outro ponto destacado é como essas relações sociais virtuais influenciam nas relações sociais ditas presenciais, e como isso impacta na sociedade em seus vários ramos como também no mundo do trabalho, por meio da dinamicidade e a fluidez que se dão essas relações, e que irá influenciar, cada vez mais as novas gerações em todos os seus aspectos. Também é destacado diversos aspectos da computação importantes para estudos mais aprofundados, como: pensamento computacional, mundo digital e cultura digital que devem ser articulados com as competências gerais e os objetivos de aprendizagem para o desenvolvimento da Educação Infantil e nas competências específicas e habilidades dos diferentes componentes curriculares do ensino fundamental, respeitadas as distinções entre essas etapas. No que tange o ensino médio, se destaca a relação presente entre os jovens e a cultura digital, como efetivos partícipes e protagonistas nesse cenário. E por fim, define as competências e habilidades que são distribuídas por todo o ensino básico. Competências e habilidades essas, que permeiam essa 
relação com a tecnologia digital com vistas a: Instigar no estudante a busca de informações nas diferentes mídias que apresentem as vantagens e desvantagens do uso das tecnologias digitais; A apropriação do estudante com as linguagens digitais para que eles mesmos possam ser produtores e exploradores desse multiletramento, ampliando assim as possibilidades de acesso à ciência, à tecnologia, à cultura e ao trabalho; Uso de diversificadas ferramentas de softwares e aplicativos com fins a representar ou simular conhecimento ou informações através de experiências em diferentes áreas do conhecimento; e por fim, utilizar, propor ou implementar soluções envolvendo diferentes tecnologias com fins a solucionar problemas da vida cotidiana, explorando para isso o ensino de forma afetiva, o raciocínio lógico, o pensamento computacional, o espírito de investigação e a criatividade (BRASIL, 2018).

A partir dessas concepções traçadas pela BNCC percebe-se os desafios para uso das tecnologias digitais pelos professores em sua prática docente através de métodos e técnicas ativas que direcionem o aluno como centro do aprendizado. Também temos o estudante como ator ativo e participante dessa inclusão digital de forma crítica e reflexiva. Ademais, a escola não deve ficar avessa as mudanças tecnológicas ao seu derredor, e sim acompanhar e incluí-las de modo a alcançar sob outros olhares o seu fim pedagógico. Fechamos então citando o papel relevante que a BNCC destaca a compreensão e ao uso da cultura digital sob seus vários aspectos, como também a sua incorporação pelos profissionais de educação através de metodologias críticas e reflexivas, descartando o uso pelo uso e fortalecendo as formas como essas tecnologias podem ser construídas dentro do processo ensino aprendizagem do estudante.

\section{CONSIDERAÇÕES FINAIS}

Ao avaliarmos trazer à luz ao leitor as considerações finais desta pesquisa em questão, retomamos o objetivo inicial que se propôs a identificar as orientações e instigações ao uso das tecnologias digitais presentes na BNCC com fins a apresentar as instigações presentes na BNCC quanto ao uso de tecnologia digital, servindo como suporte aos atores educacionais como professores ao seu plano de estudo e de aula, os estudantes enquanto protagonistas do ensino, e aos demais atores com vistas a planejamentos macro, enquanto gestores públicos ou mesmo à equipe diretiva das instituições em direcionamentos de cunho interno.

Logo, por meio da pesquisa identificamos que a BNCC preceitua a utilização de tecnologias digitais em toda a educação básica. É de se destacar que entre as suas dez competências gerais, há duas que possuem relação com tecnologia digital. Esta orientação está vinculada na quarta e integralmente na quinta competência geral da BNCC. Em relação à quarta 
competência é destacado que deve ser instigado o uso de diferentes linguagens para o ensino, e destaca entre elas a linguagem digital. Essas linguagens serão utilizadas para expressão individual, partilha de informações, experiências, ideias e sentimentos sob contextos diversos com fins a produção de sentido que direcione ao entendimento. No que tange a quinta competência, esta é focada no uso de tecnologia digital quando orienta a compressão, utilização e criação de tecnologias digitais de maneira crítica, significativa, reflexiva e ética nas práticas sociais e virtuais do estudante, com fins ao uso na comunicação, disseminação de informações, produção de conhecimento, resolução de problemas, protagonismo de seu ensino e em sua vida cotidiana.

Ademais, como observações complementares advindas desta pesquisa ressaltamos que a BNCC não surgiu intempestivamente derivada de um ato único de um gestor, e sim em sua história recente parte desde a Constituição Federal de 1988 que vislumbrava uma base comum para o ensino no Brasil. Nos anos que se seguiram foram implementadas leis, portarias e normas técnicas nesse propósito, temos que destacar dentre essas normativas a LDB. Ademais, ao se examinar a BNCC percebe-se que a instigação ao uso de tecnologias digitais se espalha por todo o corpus do texto, e em todas as etapas da educação básica. Essas instigações se dispõem a partir de tópicos específicos como: as competências gerais - a quarta e a quinta; as competências específicas de cada área que orientam o uso das tecnologias digitais em todos os componentes curriculares; e por fim o item denominado: as tecnologias digitais e a computação. Nele destaca-se a importância do estudante se apropriar das tecnologias digitais tanto para o seu protagonismo no estudo, quanto para sua vida cotidiana.

Ainda que saibamos dos embates - às vezes desiguais - por conta do poder econômico, político e social promovidos por atores diversos de esfera privada e pública, aos quais suas vozes se fazem ouvir do centro ou das fronteiras em um contexto de dinâmica social, refletem diretamente nas legislações educacionais. Conquanto, compreendemos que os resultados desta pesquisa corroboram autores que salientam que a BNCC trouxe algumas contribuições relevantes e dentre elas a instigação ao uso das tecnologias digitais, pois isto, não pode ser vilipendiado tendo em vista a necessidade de apropriação pelos alunos e professores das diversas ferramentas que se fazem presentes hoje em dia, uma vez que a tecnologia digital está em todos os campos da atividade humana, e assim é recomendado ser-lhe minimamente conhecedor. 
Importante realçarmos que, ainda quando tenhamos atingido os objetivos propostos nessa pesquisa, há dimensões que tangem a BNCC que não foram contempladas neste estudo, pois há um panorama maior que não está restrito apenas a instigação do uso de tecnologias digitais, como por exemplo os embates entre os atores públicos e privados no que se refere a composição final desta normativa ou mesmo quem foi favorecido por esta redação. Desse modo, outras investigações podem ser aprofundadas sob novos olhares direcionados ao objeto BNCC. Temos então novas direções que podem ser percorridas.

\section{REFERÊNCIAS}

BEHAR, Patrícia A. A validação de objetos de aprendizagem para formação de professores de Educação Infantil. CINTED-UFRGS. Novas Tecnologias na Educação, Porto Alegre, v. 6, n. 1, p. 1-11, jul. 2008.

BRASIL. Constituição da República Federativa do Brasil: promulgada em 5 de outubro de 1988, 1988. Disponível em:

http://www.planalto.gov.br/ccivil_03/constituicao/constituicao.htm. Acesso em: 14 maio 2020.

BRASIL. Lei no 9.394 de 20 de dezembro de 1996. Estabelece as diretrizes e bases da educação nacional., 1996. Disponível em:

http://www.planalto.gov.br/ccivil_03/leis/19394.htm. Acesso em: 16 maio 2020.

BRASIL. MEC. Base Nacional Comum Curricular, 2018. Disponível em:

http://basenacionalcomum.mec.gov.br/images/BNCC_EI_EF_110518_versaofinal_site.pdf. Acesso em: 06 fev. 2020.

COSTA, Sandra Regina Santana; DUQUEVIZ, Barbara Cristina; PEDROZA, Regina Lúcia Sucupira. Tecnologias Digitais como instrumentos mediadores da aprendizagem dos nativos digitais. Revista Quadrimestral da Associação Brasileira de Psicologia Escolar e Educacional, São Paulo-SP, v. 19, n. 3, p. 603-610, set/dez 2015. ISSN 10.1590/21753539/2015/0193912. Disponível em: https://www.scielo.br/pdf/pee/v19n3/2175-3539-pee-1903-00603.pdf. Acesso em: 28 maio 2020.

ENGUITA, Mariano Fernández. Educar em tempos incertos. Tradução Fátima Murad. Porto Alegre: Artmed, 2004.

GIL, Antônio Carlos. Como elaborar projetos de pesquisa. 4. ed. São Paulo: Atlas, 2002.

KENSKI, Vani Moreira. O papel do professor na sociedade. In: CARVALHO, A. M. P. D.; CASTRO, A. D. D. Ensinar a Ensinar. São Paulo: Pioneira, 2001. p. 226.

LIBÂNEO, José Carlos; OLIVEIRA, João Ferreira de; TOSCHI, Mirza Seabra. Educação Escolar: políticas, estrutura e organização. São Paulo: Cortez, 2003.

MORIN, Edgar. Introdução ao pensamento complexo. 3. ed. Porto Alegre: Sulina, 2007. 
PARADA, Eloa Azzena. TICs na escola: balanço de teses e dissertações brasileiras produzidas no período de 1990 a 2010. Dissertação (Mestrado em Educação) Programa de Pós-Graduação em Educação: Currículo, Pontifícia Universidade Católica de São Paulo/PUCSP. São Paulo, p. 137. 2011.

REIS, Geovana; OLIVEIRA, Joao Ferreira de. PUC. A Constituição do Currículo Escolar no Brasil: Dilemas, Impasses e Perpectivas, 2018. Disponível em: https://sites.pucgoias.edu.br/pos-graduacao/mestrado-doutorado-educacao/wpcontent/uploads/sites/61/2018/05/Geovana-Reis_-Joao-Ferreira-de-Oliveira.pdf. Acesso em: 16 abr. 2021.

SAVIANI, Demerval. Escola e democracia. 24. ed. São Paulo: Cortez, 1991.

SILVA, Thayse de Oliveira; SILVA, Lebiam Tamar Gomes. Os impactos sociais, cognitivos e afetivos sobre a geração de adolescentes conectados às tecnologias digitais. Rev. psicopedag., São Paulo, v. 34, n. 103, p. 87-97, 2017. Disponível em: http://pepsic.bvsalud.org/scielo.php?script=sci_arttext\&pid=S010384862017000100009\&lng=pt\&nrm=iso. Acesso em: 28 maio 2020. 